\title{
Analysis of Bacterial and Archaeal Communities along a High-Molecular-Weight Polyacrylamide Transportation Pipeline System in an Oil Field
}

\author{
Cai-Yun Li ${ }^{1}$, Jing-Yan $\mathrm{Li}^{2}$, Serge Maurice Mbadinga ${ }^{1}$, Jin-Feng Liu ${ }^{1}$, Ji-Dong Gu ${ }^{3}$ \\ and Bo-Zhong Mu ${ }^{1, *}$
}

1 State Key Laboratory of Bioreactor Engineering and Institute of Applied Chemistry, East China University of Science and Technology,130 Meilong Road, Shanghai 200237, China;

E-Mails: licaiyun@mail.ecust.edu.cn (C.-Y.L.); smmbadinga@ecust.edu.cn (S.M.M.); 1jf@ecust.edu.cn (J.-F.L.)

2 Daqing Oilfield Limited Company, Daqing 163453, China; E-Mail: 1jingyan@petrochina.com.cn

3 School of Biological Sciences, The University of Hong Kong, Pokfulam Road, Hong Kong, China; E-Mail: jdgu@hkucc.hku.hk

* Author to whom correspondence should be addressed; E-Mail: bzmu@ecust.edu.cn; Tel.: +86-21-6425-2063; Fax: +86-21-6425-2485.

Academic Editor: Masato Matsuoka

Received: 29 October 2014 / Accepted: 19 March 2015 / Published: 2 April 2015

\begin{abstract}
Viscosity loss of high-molecular-weight partially hydrolyzed polyacrylamide (HPAM) solution was observed in a water injection pipeline before being injected into subterranean oil wells. In order to investigate the possible involvement of microorganisms in HPAM viscosity loss, both bacterial and archaeal community compositions of four samples collected from different points of the transportation pipeline were analyzed using PCR-amplification of the 16S rRNA gene and clone library construction method together with the analysis of physicochemical properties of HPAM solution and environmental factors. Further, the relationship between environmental factors and HPAM properties with microorganisms were delineated by canonical correspondence analysis (CCA). Diverse bacterial and archaeal groups were detected in the four samples. The microbial community of initial solution S1 gathered from the make-up tank is similar to solution S2 gathered from the first filter, and that of solution S3 obtained between the first and the second filter is similar to that of solution S4 obtained between the second filter and the injection well. Members of the genus Acinetobacter sp. were detected with high abundance in S3 and S4
\end{abstract}


in which HPAM viscosity was considerably reduced, suggesting that they likely played a considerable role in HPAM viscosity loss. This study presents information on microbial community diversity in the HPAM transportation pipeline and the possible involvement of microorganisms in HPAM viscosity loss and biodegradation. The results will help to understand the microbial community contribution made to viscosity change and are beneficial for providing information for microbial control in oil fields.

Keywords: microbial community; 16S rRNA gene; CCA; oilfield; HPAM degradation

\section{Introduction}

Partially hydrolyzed polyacrylamide with high-molecular-weight has been employed extensively as an oil-displacing agent for enhanced oil recovery in the petroleum industry [1,2]. A viscosity loss of the HPAM solution occurred in a consecutive transportation pipeline of a water injection system after six years operation. Subsequently this viscosity loss caused a decrease in oil recovery. The factors contributing to viscosity loss of the HPAM solution are speculated to be $\mathrm{pH}$, temperature, salinity, mechanical force, shear force and microbial degradation. With the exception of microbial degradation [3], the other factors are controllable and have been studied thoroughly [4-6]. It has been reported that microorganisms are capable of metabolizing polymers and low-molecular-weight polymerization products [7], and bacteria such as Bacillus sphaericus, Acinetobacter sp., Bacillus cereus and Bacillus sp. isolated from soils and oilfields have been directly implicated in the biodegradation of HPAM by hydrolyzing the amide chain or cleaving the carbon chain to reduce HPAM viscosity [8].

With the advantage of the development of deoxyribonucleic acid (DNA)-based molecular techniques, microbial communities may be characterized more accurately and many microorganisms including culturable and non-culturable ones were identified in environments like soil [9], seawater [10], inland water [11] and oilfields [12-14]. Recently, the microbial communities in oilfields both of high and low temperatures have been analyzed [15-17]. The microbial communities related to the viscosity loss of the HPAM solution need to be analyzed.

In this study, the bacterial and archaeal compositions in different samples along the transportation pipeline were analyzed employing PCR (polymerase chain reaction)-amplification of 16S rRNA (ribonucleic acid) gene and clone library construction method. The corresponding relationship between environmental conditions and HPAM properties with microbial communities were revealed by CCA.

\section{Results and Discussion}

In this work, four samples were collected. They are the initial solution of sample 1 (S1) collected from make-up tank; Sample 2 solution (S2) gathered from the first filter; Sample 3 solution (S3) obtained between the first and the second filter; Sample 4 solution (S4) obtained between the second filter and the injection well, respectively. The diagram of the water injection system and sampling sites are shown in Figure 1. 


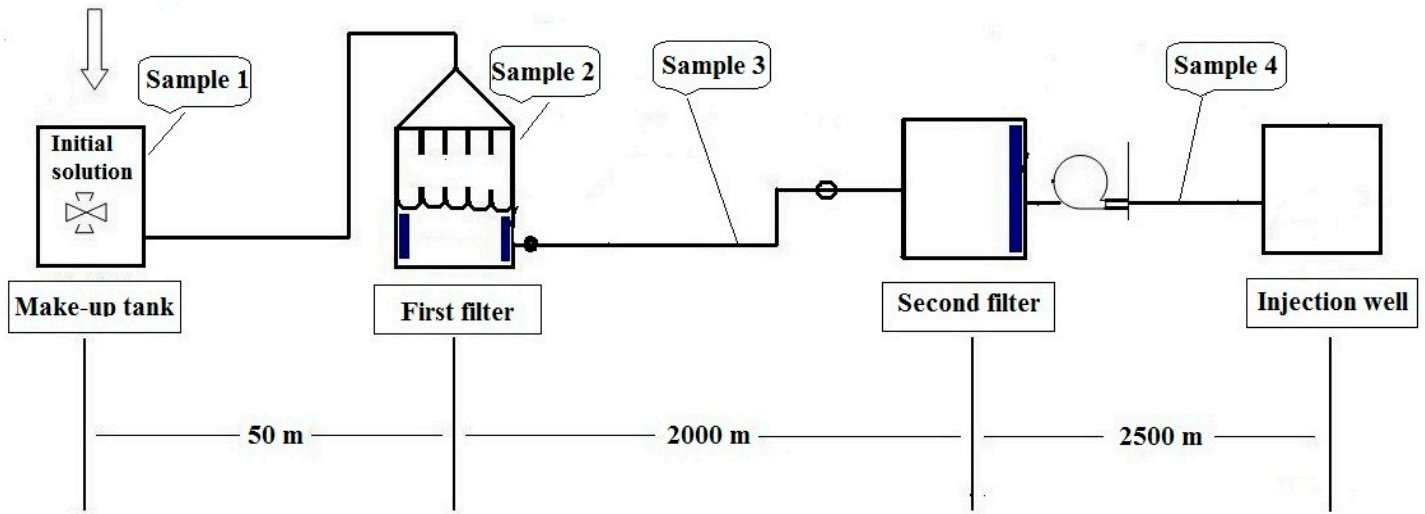

Figure 1. Schematic diagram showing the water injection system and the sampling sites.

\subsection{Physicochemical Information of Samples}

Environmental factors and HPAM physicochemical properties of the samples were measured using different chemical methods (Table 1).

Table 1. Environmental factors and HPAM physicochemical properties of samples.

\begin{tabular}{|c|c|c|c|c|}
\hline Samples & S1 & S2 & S3 & S4 \\
\hline Temperature $\left({ }^{\circ} \mathrm{C}\right)$ & 25 & 24 & 23 & 24 \\
\hline Sampling distance (m) & 0 & 50 & 1500 & 2050 \\
\hline $\mathrm{pH}$ & 6.68 & 7.50 & 7.52 & 7.59 \\
\hline Solids content $(\%)$ & 0.451 & 0.596 & 0.554 & 0.469 \\
\hline Viscosity $(\mathrm{mPa} \cdot \mathrm{S})$ & 1320 & 1071 & 1056 & 865 \\
\hline $\mathrm{Na}^{+}\left(\mathrm{mg} \cdot \mathrm{L}^{-1}\right)$ & 805.0 & 689.0 & 466.0 & 442.0 \\
\hline $\mathrm{K}^{+}\left(\mathrm{mg} \cdot \mathrm{L}^{-1}\right)$ & 38.1 & 26.2 & 31.1 & 6.1 \\
\hline $\mathrm{Ca}^{2+}\left(\mathrm{mg} \cdot \mathrm{L}^{-1}\right)$ & 43.5 & 23.1 & 46.3 & 64.0 \\
\hline $\mathrm{Mg}^{2+}\left(\mathrm{mg} \cdot \mathrm{L}^{-1}\right)$ & 11.0 & 15.9 & 9.1 & 14.0 \\
\hline $\mathrm{Cl}^{-}\left(\mathrm{mg} \cdot \mathrm{L}^{-1}\right)$ & 709.0 & 144.2 & 473.0 & 173.0 \\
\hline $\mathrm{NH}_{4}^{+}\left(\mathrm{mg} \cdot \mathrm{L}^{-1}\right)$ & 160.5 & 60.4 & 95.0 & 62.0 \\
\hline $\mathrm{NO}_{3}^{-}\left(\mathrm{mg} \cdot \mathrm{L}^{-1}\right)$ & 11.0 & 15.4 & 48.9 & 9.0 \\
\hline $\mathrm{SO}_{4}{ }^{2-}\left(\mathrm{mg} \mathrm{L}^{-1}\right)$ & 561.3 & 298.5 & 190.0 & 58.7 \\
\hline $\mathrm{PO}_{4}{ }^{3-}\left(\mathrm{mg} \cdot \mathrm{L}^{-1}\right)$ & $\mathrm{Nd}$ & $\mathrm{Nd}$ & $\mathrm{Nd}$ & $\mathrm{Nd}$ \\
\hline Formate $\left(\mathrm{mg} \cdot \mathrm{L}^{-1}\right)$ & $\mathrm{Nd}$ & 0.16 & $\mathrm{Nd}$ & $\mathrm{Nd}$ \\
\hline Acetate $\left(\mathrm{mg} \cdot \mathrm{L}^{-1}\right)$ & 0.14 & 2.82 & 3.68 & 2.15 \\
\hline Propionate $\left(\mathrm{mg} \cdot \mathrm{L}^{-1}\right)$ & $\mathrm{Nd}$ & 0.10 & $\mathrm{Nd}$ & $\mathrm{Nd}$ \\
\hline Butyrate $\left(\mathrm{mg} \cdot \mathrm{L}^{-1}\right)$ & 0.01 & 0.17 & $\mathrm{Nd}$ & $\mathrm{Nd}$ \\
\hline $\mathrm{H}_{2}\left(\mathrm{mmol} \cdot \mathrm{L}^{-1}\right)$ & $\mathrm{Nd}$ & 0.06 & $\mathrm{Nd}$ & $\mathrm{Nd}$ \\
\hline $\mathrm{CH}_{4}\left(\mathrm{mmol} \cdot \mathrm{L}^{-1}\right)$ & $\mathrm{Nd}$ & 1.36 & 0.92 & 0.05 \\
\hline $\mathrm{CO}_{2}\left(\mathrm{mmol} \cdot \mathrm{L}^{-1}\right)$ & $\mathrm{Nd}$ & 32.35 & 4.14 & 7.97 \\
\hline HPAM concentration $\left(\mathrm{mg} \cdot \mathrm{L}^{-1}\right)$ & 5240 & 4280 & 4010 & 2940 \\
\hline HPAM hydrolysis degree (\%) & 32.55 & 35.07 & 39.65 & 41.13 \\
\hline $\operatorname{HPAM} M_{\eta}\left(\times 10^{6}\right)$ & 17 & 6.24 & 5.49 & 2.12 \\
\hline $\operatorname{HPAM} R_{\mathrm{h}}(\mathrm{nm})$ & 2394.8 & 692.5 & 573.5 & 282.1 \\
\hline HPAM PDI & 0.363 & 0.318 & 0.312 & 0.436 \\
\hline
\end{tabular}

(Nd: undetected; $M_{\eta}$ : viscosity-average molecular weight; $R_{\mathrm{h}}$ : hydrodynamic radius; PDI: Polydispersity index). 
HPAM properties of viscosity, concentration, $M_{\eta}$ and $R_{\mathrm{h}}$ were decreasing, but the hydrolysis degree and $\mathrm{pH}$ are increasing with the sampling distance from S1 to S4. Laser light scattering testing (LLS) results of $R_{\mathrm{h}}$ and PDI are shown in Figure $\mathrm{S} 1 . R_{\mathrm{h}}$ results indicated that the particle size of HPAM in the samples were reduced, which partially come from $M \mathrm{w}$ (molecular weight) changing especially for the lowest $R \mathrm{~h}$ ones and lower Mw of HPAM can indicate HPAM degradation. Volatile fatty acids (formate, acetate, propionate and butyrate) were measured and high content of acetate were found in S2, S3 and S4 than in S1. The results indicated that the volatile fatty acids were mainly produced in this system. The detection of $\mathrm{H}_{2}, \mathrm{CH}_{4}$ and $\mathrm{CO}_{2}$ indicates the possibility of methanogens and sulfate-reducing bacteria (SRB) existing in the community. In addition, unpleasant smell, characteristic of $\mathrm{H}_{2} \mathrm{~S}$, occurs in the samples of $\mathrm{S} 2, \mathrm{~S} 3$ and S4 when sampling.

\subsection{Bacterial and Archaeal Community Compositions}

The obtained 16S rRNA gene sequences belong to different operational taxonomic units (OTUs) and all of the valid sequences and OTUs were counted. The coverage and Shannon-Wiener index were calculated as shown in Table 2. Bacterial and archaeal community compositions were analyzed using phylogenetic analyses of 16S rRNA gene clone library [18].

Table 2. 16S rRNA gene and clone library analysis information of samples.

\begin{tabular}{|c|c|c|c|c|}
\hline Samples & S1 & S2 & S3 & S4 \\
\hline \multicolumn{5}{|c|}{ Bacteria } \\
\hline Valid sequences & 159 & 70 & 80 & 121 \\
\hline OTU & 15 & 26 & 12 & 25 \\
\hline Coverage & 0.9000 & 0.8143 & 0.9000 & 0.8843 \\
\hline Shannon-Wiener index (nats) & 0.8035 & 2.8780 & 1.5009 & 2.3415 \\
\hline \multicolumn{5}{|c|}{ Archaea } \\
\hline Valid sequences & 30 & 78 & 102 & 29 \\
\hline OTU & 14 & 6 & 6 & 6 \\
\hline Coverage & 0.7000 & 0.9615 & 0.9608 & 0.8966 \\
\hline Shannon-Wiener index & 2.2465 & 1.0857 & 0.4670 & 1.3863 \\
\hline
\end{tabular}

All of the gene sequences are affiliated with the members of the phyla Proteobacteria, Spirochaetes, Lentisphaerae and Bacteroidetes and the classes of Betaproteobacteria, Gammaproteobacteria, Epsilonproteobacteria, Deltaproteobacteria, Alphaproteobacteria, Spirochaetes, Lentisphaeria, Sphingobacteria and Flavobacteriia. The results are presented in two phylogenetic trees (Figure 2a,b); (note: The microorganisms in sample S1 are represented by the microbial communities in the tap water for dissolving HPAM). The gene sequences from different samples are assigned with different colors: $\mathrm{S} 1$ in yellow, S2 in green, S3 in blue and S4 in red.

The relative abundances of bacterial orders were determined and are shown in Figure 3. 


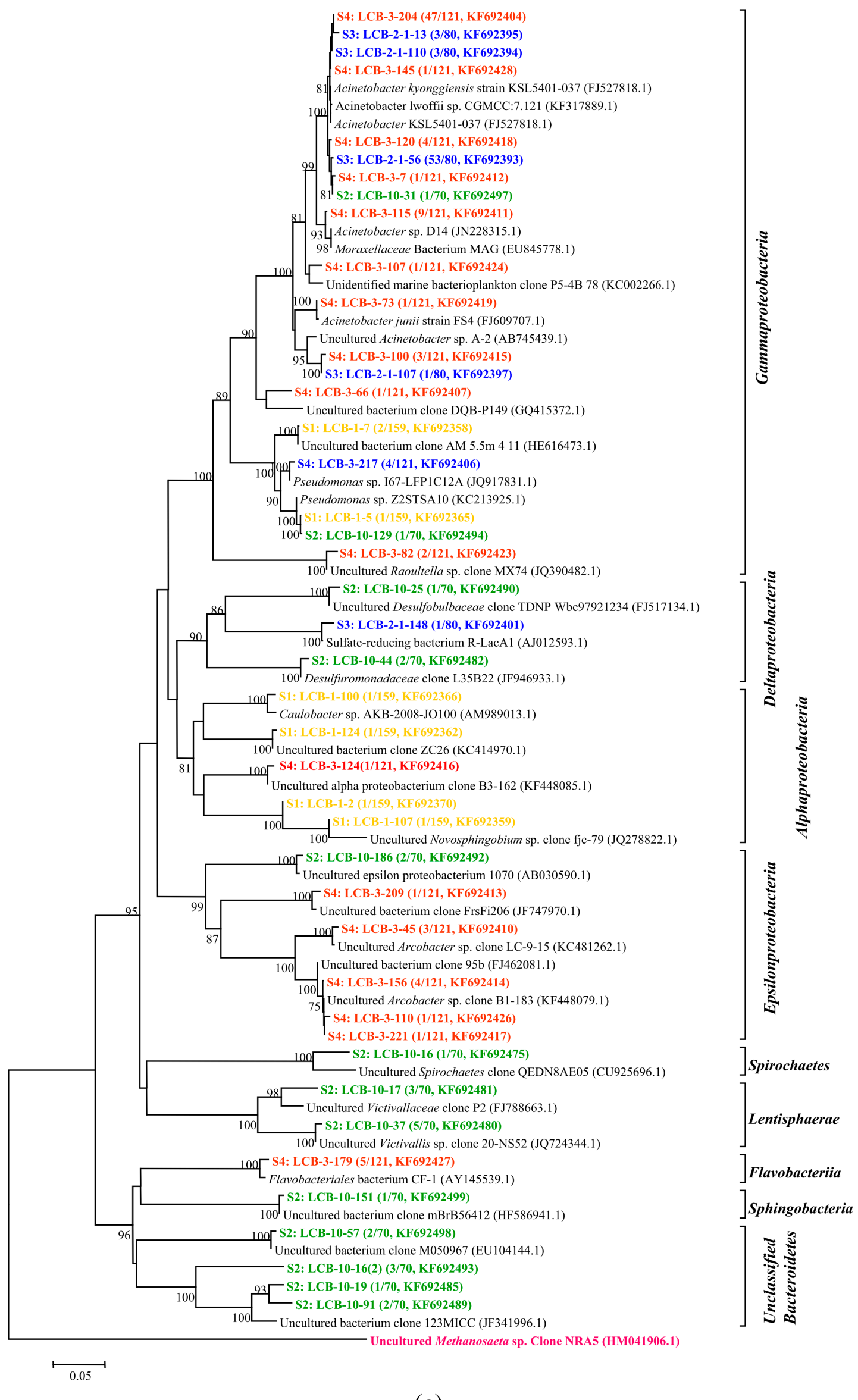

(a)

Figure 2. Cont. 


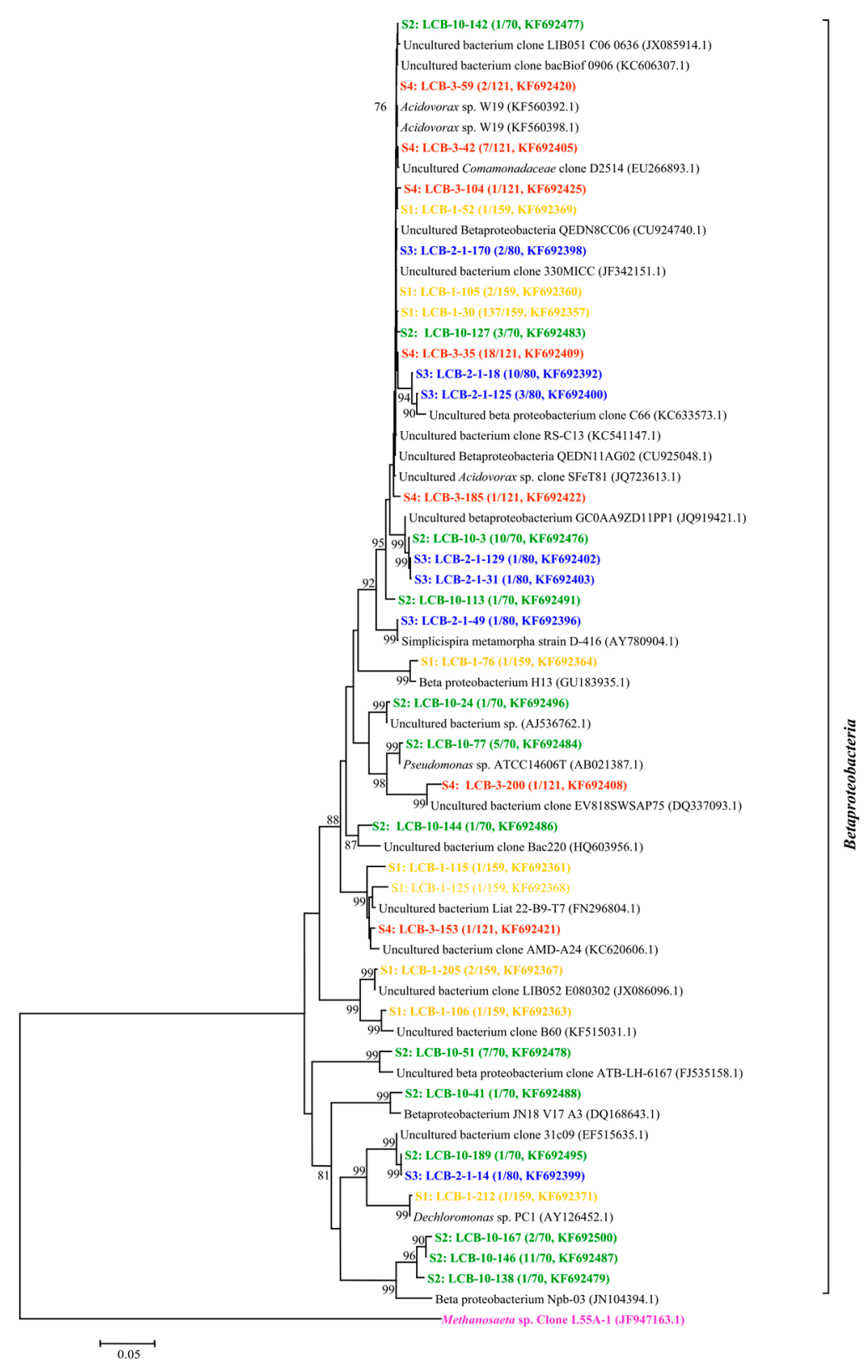

(b)

Figure 2. (a) Phylogenetic tree of bacterial 16S rRNA gene clones retrieved from four samples showing the distributions of OTUs and closely related sequences from GenBank database. The bootstrap values at the nodes of $\geq 75 \%$ ( $n=1000$ replicates) are reported. The scale bar represents 5\% sequence divergence. The numbers in parentheses indicate the frequencies of appearance of identical clones in the total analyzed clones followed the accession number in GenBank. Methanosaeta sp. clone was used as outgroup; (b) Phylogenetic tree of bacterial 16S rRNA gene clones retrieved from samples showing the distributions of OTUs and closely related sequences from GenBank database. The bootstrap values at the nodes of $\geq 75 \%$ ( $n=1000$ replicates) are reported. The scale bar represents $5 \%$ sequences divergence. The numbers in parentheses indicate the frequencies of appearance of identical clones in the total analyzed clones followed the accession number in GenBank. The Methanosaeta sp. clone was used as outgroup. The gene sequences from different samples are assigned with different colors: S1 in yellow, S2 in green, S3 in blue and S4 in red. 
The relative abundances of bacterial orders were determined and are shown in Figure 3.
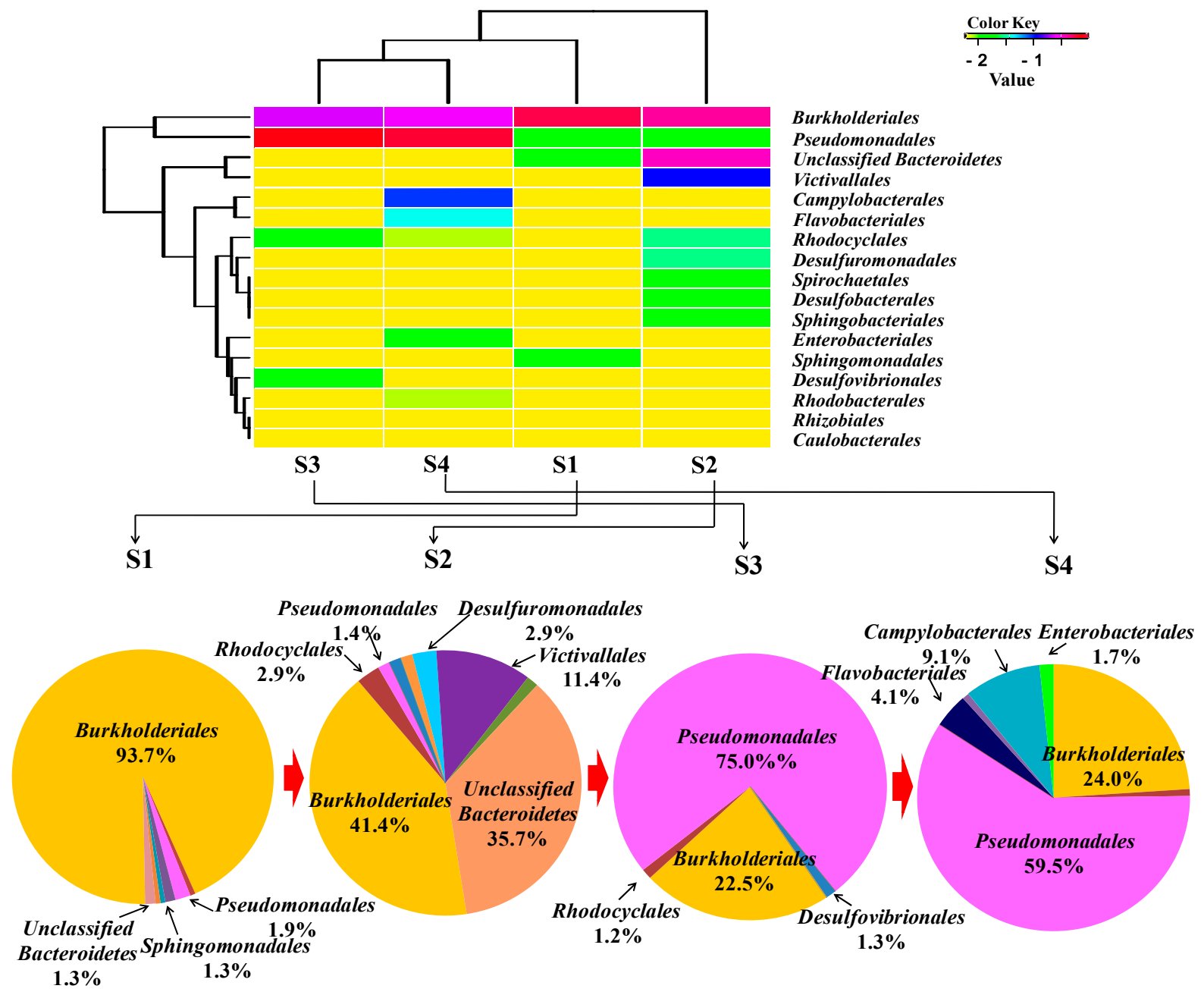

Figure 3. Relative abundance of bacterial orders detected in samples of an oilfield pipeline.

Along the transportation pipeline, the bacterial community compositions from sample 1 (S1) to sample 4 (S4) changed. Burkholderiales and Pseudomonadales are the main dominating orders compared with the other community. However, the Burkholderiales decreased in abundance from $94 \%$ to $24 \%$, with increasing distance from the make-up tank, whereas the Pseudomonadales increased in relative abundance from $2 \%$ to $60 \%$. Rhodocyclales remained at low abundance from $0.6 \%$ to $0.8 \%$ with a bit of an increase to $2.9 \%$ and $1.3 \%$ in S2 and S3, respectively. Sulfate-reducing bacteria of Desulfobacterales (1.4\%), Desulfuromonadales (2.9\%) and Desulfovibrionales (1.3\%) were detected in S2 and S3, respectively. Campylobacterales (9.1\%), Enterobacteriales (1.7\%) and Flavobacteriales (4.1\%) were only shown in S4. The heat map was drawn [19] and is also shown in Figure 3, which displays that the bacterial community compositions of S1 are close to those of S2 and those of S3 are close to S4. From Burkholderiales to Caulobacterales, the abundance of each order is decreasing following the sequence from top to bottom.

Through the analysis of HPAM physicochemical properties, it was found that the viscosity of HPAM gradually decreased along the transportation pipeline, especially from S3 to S4. As some bacteria are heterotrophs, they can utilize carbohydrates as sources. HPAM also can be used as $\mathrm{N}, \mathrm{C}$ or $\mathrm{C} / \mathrm{N}$ sources 
in this environment. Some isolates were reported of being responsible for HPAM biodegradation directly, but unfortunately their sequences information is not available in the GenBank database. For example, Enterobacter agglomerans utilized HPAM as sole carbon or nitrogen source and degraded high $M \mathrm{w}$ HPAM to low Mw ones [20]. The same order of Enterobacteriales was found in S4. Pseudomonas migula CJ419 was found to degrade HPAM viscosity by $30.4 \%$ [21], and bacteria belonging to Pseudomonadales sp. occurred with high abundance in both S3 and S4. SRB of Clostridium bifermentans $\mathrm{H} 1$ was found to utilize HPAM as sole carbon source, hydrolyze the amide group, degrade the side chain and change some functional groups, which finally results in reducing HPAM viscosity [22]. SRB also reduced the viscosity of $1000 \mathrm{mg} / \mathrm{L}$ HPAM solution by $20 \%$ after seven days of cultivation at $30{ }^{\circ} \mathrm{C}$ [23]. Similarly, SRB were detected in S2 and S3 including Desulfovibrionales in S3, Desulfobacterales and Desulfuromonadales in S2. The SRB metabolic product of sulfide was proved to reduce HPAM viscosity as well [24]. Acinetobacter sp. can degrade HPAM reducing its molecular weight and lowering viscosity by $78 \%$ [8]. These bacteria were detected in both S3 and S4 with high appearance frequency. HPAM viscosity reduced significantly from 1056 to $865 \mathrm{mPa} \cdot \mathrm{S}$, and from $\mathrm{S} 3$ to $\mathrm{S} 4$, and Acinetobacter sp. occurred with high abundance indicating that these bacteria have a large potential to be the main microorganisms to reduce HPAM viscosity.

Although isolates such as Bacillus cereus HWBI, Bacillus flexu HWBII, Bacillus cereus PM-2 and Bacillus sp. PM-3 were described to utilize polyacrylamide such as nitrogen and carbon sources [3,25], they were not detected in the analysis results of four samples. For other bacteria detected in the samples, their possible participation in HPAM biodegradation is not known. Sphingobacteriales are a main member of the Bacteroidetes and its principal genus is Cytophaga, which can degrade cellulose [26]. Victivallales is an uncultured bacterium, and was detected in bovine rumen, which has an auxiliary function on vegetal fiber degradation [27]. Flavobacterials can be used to degrade a mixture of anthracene, phenanthrene and pyrene [28]. Thus, these groups may possibly participate in HPAM biodegradation.

Archaea are essential and occurred together with bacteria. Archaeal community compositions were analyzed employing the same steps as the above bacterial community analysis and four specific groups were detected, as shown in Figure 4.

Based on the phylogenetic analysis, the relative abundance of archaeal orders in the samples from S1 to S4 was determined and is shown in Figure 5.

Along the transportation pipeline, Methanomicrobiales and Methanosarcinales are the two main orders occurring in the samples from S2 to S4. Methanosarcinales occurred in S2 with the relative abundance of 50\%, in S3 with $91.7 \%$ and finally in S4 with 77.4\% abundance. Methanomicrobiales occurred in S2 with 50\% abundance but in S4 with only 19.4\%. Methanobacteriales were detected twice with 3.2\% abundance, respectively. The heat map also showed that archaeal communities of S3 are close to those of S4 (Figure S2). 


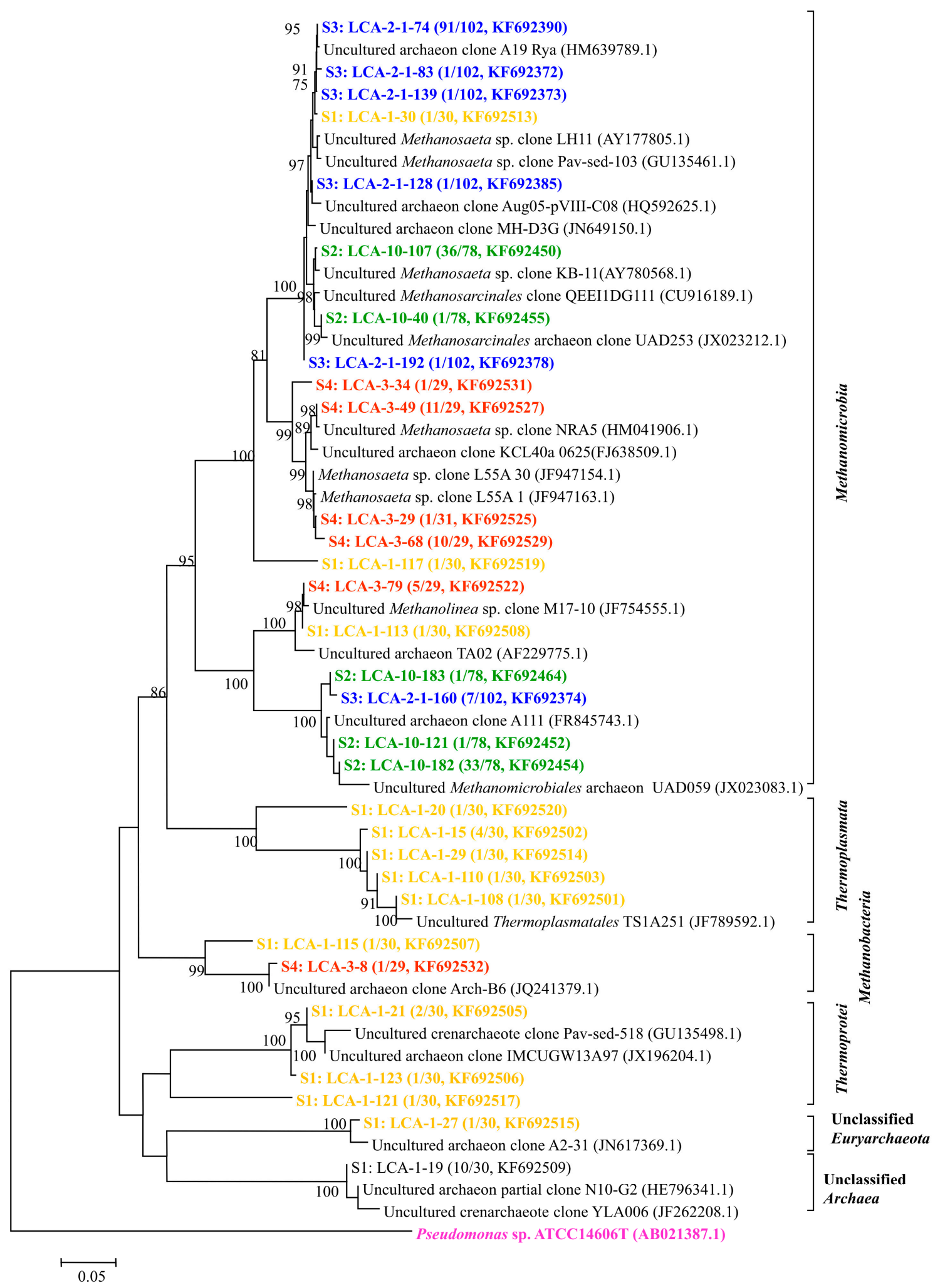

Figure 4. Phylogenetic tree of archaeal clones from the samples of S1-S4 showing the distributions of OTUs and closely related sequences from GenBank database. The bootstrap values at the nodes of $\geq 75 \%$ ( $n=1000$ replicates $)$ are reported. The scale bar represents $5 \%$ sequences divergence. The numbers in parentheses indicate the frequencies of appearance of identical clones in the total analyzed clones followed with the accession number. Pseudomonas sp. clone ATCC14606 was used as outgroup. 


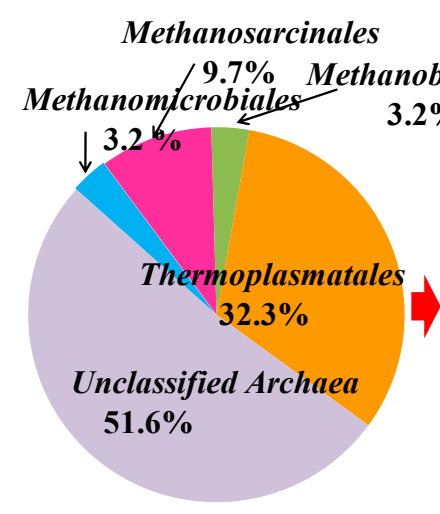

$\underline{\underline{\text { 1 }}}$

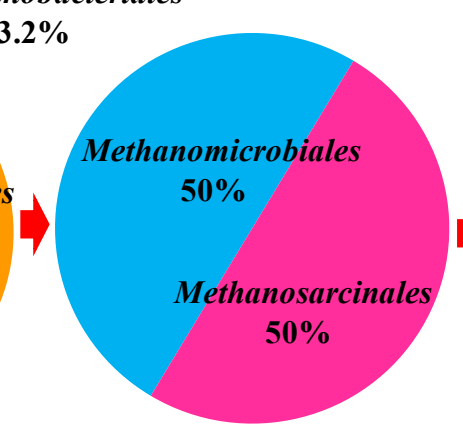

$\underline{\mathbf{S 2}}$

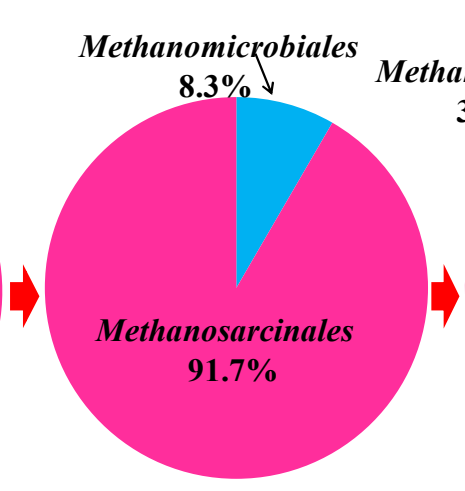

$\underline{\underline{\mathbf{S 3}}}$
Methanomicrobiales thanobacteriales $19.4 \%$

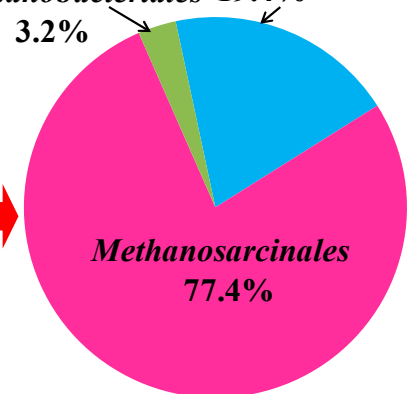

$\underline{\underline{\mathrm{S4}}}$

Figure 5. Relative abundance of archaeal orders detected in S1-S4 samples from an oilfield pipeline.

Archaea were generally found to thrive in harsh environments, but they are also found in soil, ocean, marshland and oilfields [29]. Three orders of archaea were detected in all samples including Methanobacteriales, Methanomicrobiales and Methanosarcinales, and all of them are methanogens. Methanobacteriales and Methanomicrobiales are classified to be hydrogenotrophic methanogens utilizing $\mathrm{H}_{2}$ and $\mathrm{CO}_{2}$ as substrate to generate methane [30]. Methanosarcinales are classified to be acetoclastic methanogen utilizing acetate to generate methane [15]. Since acetate, $\mathrm{H}_{2}, \mathrm{CO}_{2}$ and $\mathrm{CH}_{4}$ were separately found in four samples, only acetate comes from the tap water and some of them were supposed to be related with HPAM biodegradation. It is assumed that these archaea utilized acetate or, $\mathrm{H}_{2} / \mathrm{CO}_{2}$ to produce $\mathrm{CH}_{4}$. Methanogenesis can then accelerate HPAM biodegradation indirectly [31].

\subsection{Statistical Analysis of Canonical Correspondence Analysis (CCA)}

The correlationship between the distribution of bacterial or archaeal species and environmental factors is revealed by CCA analysis (Figure 6).

Bacterial CCA analysis revealed that the bacteria belonging to Burkholderiales, Sphingomonadales, Rhizobiales and Caulobacterales were positively correlated with temperature, $M_{\eta}$, hydrolysis degree, HPAM concentration and viscosity, the concentration of $\mathrm{Na}^{+}, \mathrm{K}^{+}$and $\mathrm{NH}_{4}{ }^{+}$. The bacteria belonging to Sphingobacteriales, Victivallales, Desulfuromonadales, Desulfobacterales, Spirochaetales and Rhodocyclales were positively correlated with the concentration of $\mathrm{Mg}^{2+}$ and $\mathrm{SO}_{4}{ }^{2-}$. The members of the Enterobacteriales, Rhodobacterales, Desulfovibrionales, Flavobacteriales, Campylobacterales and Pseudomonadales were positively correlated with $\mathrm{NO}_{3}{ }^{-}$concentration, $\mathrm{pH}$, hydrolysis degree and distance. As abundant anionic and cationic ions were detected in the samples, the $\mathrm{SO}_{4}{ }^{2-}$ can be utilized by Desulforomonadales in S2. HPAM contains many amide groups, which can be transformed into $\mathrm{NH}_{4}{ }^{+}$ and then $\mathrm{NH}_{4}{ }^{+}$can be oxidized to $\mathrm{NO}_{3}{ }^{-}$by bacteria. Desulfovibrionales have a nitrate reductase to reduce $\mathrm{NO}_{3}{ }^{-}$into $\mathrm{NH}_{4}{ }^{+}$[32]. Archaeal CCA results (Figure S3), suggesting that archaea belonging to Methanosarcinales were positively related with $\mathrm{pH}$, hydrolysis degree and $\mathrm{NO}_{3}{ }^{-}$concentration and sampling distance. Methanomicrobiales were positively related to $\mathrm{Mg}^{2+}$ and $\mathrm{SO}_{4}{ }^{2-}$ concentration. Methanobacteriales was positively related to $\mathrm{Cl}^{-}$and $\mathrm{NH}_{4}{ }^{+}$concentration. Thermoplasmatales was positively related to $M_{\eta}$, viscosity, solids content and concentrations of $\mathrm{K}^{+}$and $\mathrm{Na}^{+}$. 


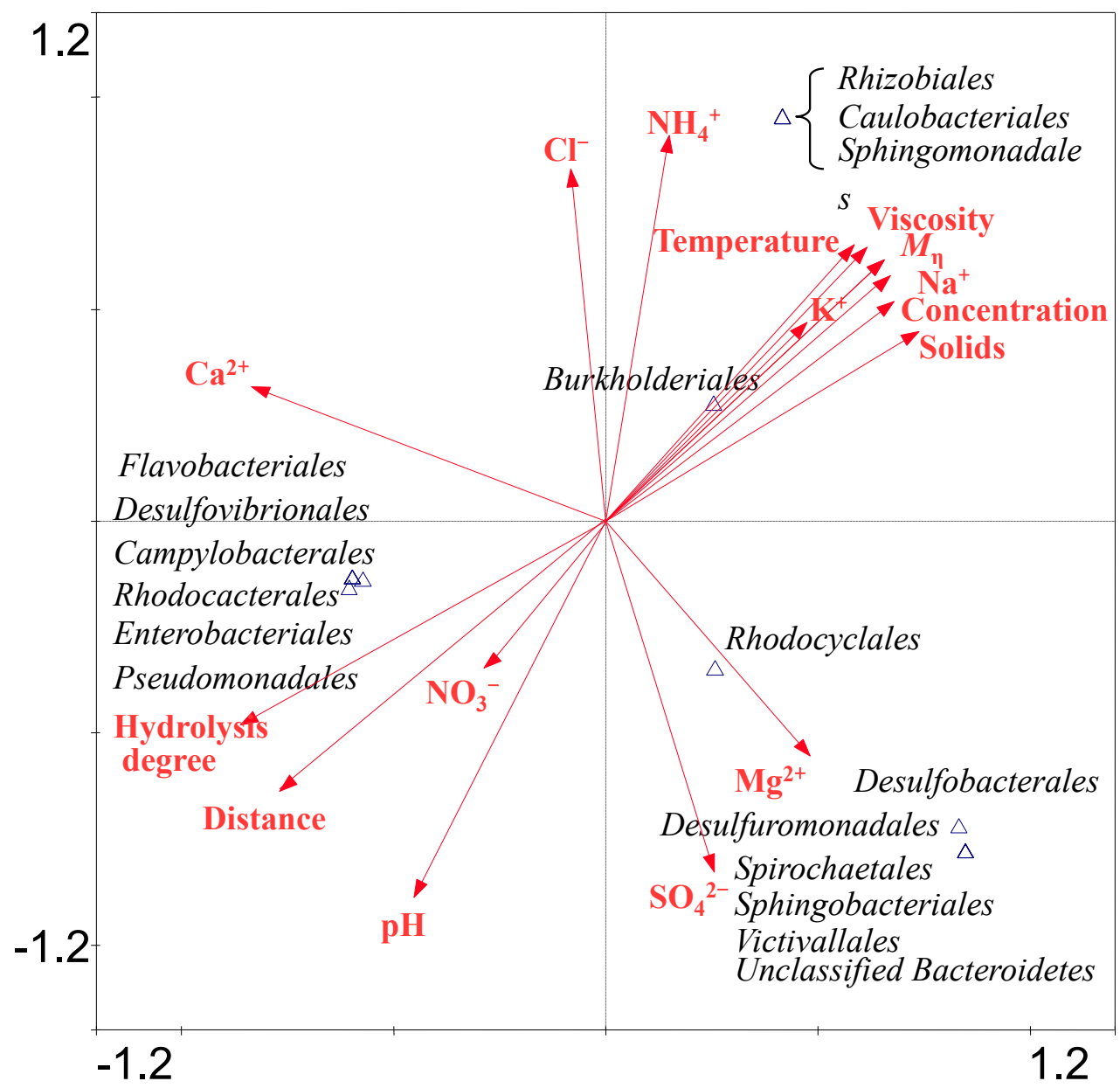

Figure 6. CCA ordination plots for the two dimensions to show the relationship between the bacterial diversity and environmental parameters analyzed using a 16S rRNA gene sequences in the water injection system of four samples. Correlations between environmental variables and CCA axes are represented by the length and angle of arrows (environmental factor vectors). Triangle means one or several species appearing position.

The above analysis of the samples indicates that the microbial community diversity has a positive correlation with HPAM physicochemical properties. It is likely that the bacteria detected in the analyzed samples were involved in reducing HPAM viscosity. It is also likely that abundant members of the genus Acinetobacter were potentially involved in HPAM biodegradation which is consistent with the large HPAM viscosity loss from S3 to S4. Implication of other groups of microorganisms in HPAM biodegradation is not excluded.

\section{Experimental Section}

\subsection{Description of Sampling}

Four samples containing HPAM (Daqing Huagong Chemical Company, Daqing, China) were taken from four different sites of the water injection system in a Daqing oil field. In this system, potable water is used to dissolve polyacrylamide to be a solution. Sample 1 through sample 4 were designated as: S1 
for initial solution containing approximately 5000 ppm of HPAM; S2 for HPAM solution prior to the first filter; S3 for HPAM solution between the first and the second filter; S4 for HPAM solution between the second filter and the injection well (Figure 1). All four samples were initially prepared with potable water [33]. Approximately ten liters of samples were collected directly into sterile containers together with the water. The containers were tightly sealed and immediately transported back to the laboratory for analysis.

\subsection{Sample Analysis}

Solid content and viscosity were tested according to the standard method SY/T5862-93 [34]. Hydrolysis content and $M_{\eta}$ (viscosity-average molecular weight) were analyzed based on the standard method GB 17514-2008 [35,36]. The content of HPAM referring as the total amount of amide-N was determined by the starch-cadmium iodide colorimetric method [37]. The concentration of formate, acetate, propionate, butyrate, anionic ions and cationic ions in samples were quantified using Dionex 600 ion chromatography (Triad Scientific, Inc., Manasquan, NJ, USA) using DIS-5C and DIS-5A suppressors. Anions were separated on an AS11 HC analytical column $(4 \times 250 \mathrm{~mm})$ with an AG11 HC guard column $(4 \times 50 \mathrm{~mm})$, (both columns, Dionex, Manasquan, NJ, USA). Cations were separated on a CS 12 A analytical column $(4 \times 250 \mathrm{~mm})$ with a CG $12 \mathrm{~A}$ guard column $(4 \times 50 \mathrm{~mm})$ [38]. Samples were measured by a laser light scattering (LLS) spectrometer (ALV/CGS-2022) equipped with an ALV-High QE APD detector and an ALV-5000 digital correlator using a He-Ne laser (wavelength $\lambda=632.8 \mathrm{~nm}$ ). The Laplace inversion of each measured intensity-intensity time correlation function $G(2)(t, q)$ is in self-beating mode, which can result in a line width distribution $G(\Gamma)$. The translational diffusion coefficient $D$ is calculated by the slope of the $\Gamma v s . q^{2}$ plot ( $\Gamma$ is decay time). Then the hydrodynamic radius $<R_{\mathrm{h}}>$ is obtained by the Stokes-Einstein equation $R_{\mathrm{h}}=k_{\mathrm{B}} T /(6 \pi \eta D),\left(k_{\mathrm{B}}, T\right.$ and $\eta$ are the Boltzmann constant, temperature, and the solvent viscosity, respectively). Polydispersity index (PDI) was determined at the scattering angle of $90^{\circ}$ [39]. The headspace gas like $\mathrm{CH}_{4}, \mathrm{H}_{2}$ and $\mathrm{CO}_{2}$ in the bottles were analyzed by gas chromatography (GC) equipped with a thermal conductivity detector (TCD) to detect $\mathrm{H}_{2}$ and a flame ionization detector (FID) for $\mathrm{CH}_{4} . \mathrm{CO}_{2}$ which is converted into $\mathrm{CH}_{4}$ by a conversion furnace (GC112A, Shanghai Precision Scientific Instrument Co., Ltd., Shanghai, China) [40].

\subsection{Nucleic Acid Extraction and PCR Amplification}

The samples were first filtered through polycarbonate membrane filters $(0.22-\mu \mathrm{m}$-pore-size, Millipore, Bedford, MA, USA) aseptically in the laboratory. Afterwards the membranes were put into a sterile centrifuge tube subjected to beads beating. Total genomic community DNA was extracted by using AxyPrep ${ }^{\mathrm{TM}}$ Bacterial Genomic DNA Maxiprep Kit (Axygen Biosciences, Inc., Santa Clara, CA, USA) and stored at $-20^{\circ} \mathrm{C}$ before testing [41,42]. Agarose gel electrophoresis $(1.0 \%, w / v)$ was used to determine the yield and integrity of DNA extraction. Universal PCR primer sets (Table 3) were applied for amplification of bacterial and archaeal 16S rRNA gene sequences, respectively [43]. 
Table 3. Primer sets information.

\begin{tabular}{cccc}
\hline Primer Set & Target Organisms & Sequences (5'-3') & Annealing Temperature \\
\hline $8 \mathrm{~F}$ & Bacteria & AGAGTTTGATYMTGGCTCAG & $52{ }^{\circ} \mathrm{C}$ \\
$805 \mathrm{R}$ & Bacteria & GACTACCAGGGTATCTAATCC & $52{ }^{\circ} \mathrm{C}$ \\
A109F & Archaea & ACKGCTCAGTAACACGT & $60{ }^{\circ} \mathrm{C}$ \\
A1041R & Archaea & GGCCATGCACCWCCTCTC & $60{ }^{\circ} \mathrm{C}$ \\
\hline
\end{tabular}

The reaction mixture for PCR amplification contained $9 \mu \mathrm{L}$ sterile ultrapure water, $2 \times$ Taq PCR Master Mix (Tiangen Biotech Co., Ltd., Beijing, China), $1 \mu \mathrm{L}$ of the forward and reverse primers in one primer set (GenScript Co., Ltd., Nanjing, China), and $2 \mu$ L DNA template (80 ng DNA templates [44]). PCR amplification reaction was performed under the following conditions: initial denaturation of DNA at $94{ }^{\circ} \mathrm{C}$ for $1 \mathrm{~min}$, followed by 30 cycles of $1 \mathrm{~min}$ denaturation at $94{ }^{\circ} \mathrm{C}$, primer annealing at $52{ }^{\circ} \mathrm{C}$ (for bacteria) $/ 60{ }^{\circ} \mathrm{C}$ (for archaea) for $1 \mathrm{~min}$ and extension at $72{ }^{\circ} \mathrm{C}$ for $1 \mathrm{~min}$, and a final extension step at $72{ }^{\circ} \mathrm{C}$ for $10 \mathrm{~min}$.

\subsection{S rRNA Gene Clone Sequencing and Accession Numbers}

The PCR products were gel-purified (U-Gene Gel Extraction kit II, Shanghai, China). Purified bacterial and archaeal DNAs were ligated with pMD $^{\circledR} 19-\mathrm{T}$ simple vector (Takara Biomedical Technology, Dalian, China) by adding $4.5 \mu \mathrm{L}$ of DNA and $0.5 \mu \mathrm{L}$ of $\mathrm{pMD}^{\circledR} 19-\mathrm{T}$ Simple vector to a $200 \mu \mathrm{L}$ centrifugal tubes for reaction at $4{ }^{\circ} \mathrm{C}$ overnight. The ligated DNAs were then transformed into the competent Escherichia coli cells according to the manufacturer's instruction (Shanghai Lifefeng Biotech Co., Ltd., Shanghai, China). The inserted 16S rRNA gene fragments were screened by PCR amplification with the vector specific primer set of M13-47 (5'-CGCCAGGGTTTTCCCAGT CACGAC-3') and RV-M (5'-GAGCGGATAACAATTTCACACAGG-3'). The reactions were carried out under the following conditions: Initial DNA denaturation at $95{ }^{\circ} \mathrm{C}$ for $5 \mathrm{~min}, 20$ cycles of $1 \mathrm{~min}$ denaturation at $94{ }^{\circ} \mathrm{C}$, primer annealing at $52{ }^{\circ} \mathrm{C}$ for $1 \mathrm{~min}$, and extension at $72{ }^{\circ} \mathrm{C}$ for $1 \mathrm{~min}$, a final extension at $72{ }^{\circ} \mathrm{C}$ for $10 \mathrm{~min}$. The positive clones in each library were selected for sequencing with an automated ABI Prism 377 analyzer by using M13-47 sequencing primer. Primers and vectors were manually removed from the obtained DNA sequences using MEGA 5.0 software [45]. Chimeric sequences were verified and removed by using Bellerophon [46]. Sequences were clustered into the same operational taxonomic units (OTUs) using FastGroup II at a 97\% similarity [47]. One representative sequence was chosen from each OTU to compare with the submitted sequences using the BLASTN network service [48]. The sequence without chimeras was initially submitted to the BLASTN program to determine their closest phylogenetic relatives. Phylogenetic trees were constructed based on the neighbor-joining algorithm using MEGA software. The confidence levels to the nodes of the consensus trees were assigned using bootstrap analysis with 1000 replicates. Partial 16S rRNA gene sequences of bacterial and archaeal genes were deposited in the GenBank database with the accession numbers from KF692357 to KF692428 and from KF692450 to KF692532, respectively. 


\title{
4. Conclusions
}

Four samples were collected along a transportation pipeline system for high-molecular-weight polyacrylamide solution to be injected in an oil field. Microbial community compositions and the physicochemical properties of the samples were analyzed. Diverse bacterial groups were detected including Betaproteobacteria, Epsilonproteobacteria, Gammaproteobacteria, Alphaproteobacteria, Deltaproteobacteria, Spirochaetes, Lentisphaeria, Sphingobacteria and Flavobacteria together with the archaeal members of the orders Methanomicrobiales, Methanosarcinales, Methanobacteriales and Thermoplasmatales. The microbial community of S1 was similar to the one of S2 and that of S3 was similar to S4. Bacteria and archaea exhibited a positive correlationship with different HPAM physicochemical properties and environmental parameters. Our data, in conjunction with other literature reports, suggest that members of the genus Acinetobacter detected with high abundance in samples S3 and S4 would have been mainly involved in HPAM viscosity loss. This work will help to understand the microbial community contribution to viscosity change in this system and are beneficial for providing information for microbial control in oil fields.

\section{Supplementary Materials}

Supplementary materials can be found at http://www.mdpi.com/1422-0067/16/04/7445/s1.

\section{Acknowledgments}

This work was supported by the National Natural Science Foundation of China (Grant No. 41273084) and the 863 Program (Grant No.2013AA064403).

\section{Author Contributions}

Cai-Yun $\mathrm{Li}$ and Jing-Yan $\mathrm{Li}$ conducted the experiments; Jin-Feng Liu, Ji-Dong Gu and Bo-Zhong Mu contributed to the conception and design; The manuscript was drafted by Cai-Yun Li and Serge Maurice Mbadinga and edited by Jin-Feng Liu, Ji-Dong Gu and Bo-Zhong Mu.

\begin{abstract}
Abbreviations
HPAM: hydrolyzed polyacrylamide; CCA: canonical correspondence analysis; LLS: laser light scattering; $M_{\mathrm{w}}$ : molecular weight; $M_{\eta}$ : viscosity-average molecular weight; $R_{\mathrm{h}}$ : hydrodynamic radius; PCR: polymerase chain reaction; RNA: ribonucleic acid; GC: gas chromatography; TCD: thermal conductivity detector; FID: flame ionization detector; DNA: deoxyribonucleic acid; OTUs: operational taxonomic units; PDI: polydispersity index; S1: sample 1; S2: sample 2; S3: sample 3; S4: sample 4.
\end{abstract}

\section{Conflicts of Interest}

The authors declare no conflict of interest. 


\section{References}

1. Sandiford, B.B. Laboratory and field studies of water floods using polymer solutions to increase oil recoveries. J. Pet. Technol. 1964, 16, 917-922.

2. Austad, T.; Taugbøl, K. Chemical flooding of oil reservoirs 2. Dissociative surfactant-polymer interaction with a negative effect on oil recovery. Colloid Surfaces A-Physicochem. Eng. Asp. 1995, 103, 73-81.

3. Bao, M.T.; Chen, Q.; Li, Y.; Jiang, G. Biodegradation of partially hydrolyzed polyacrylamide by bacteria isolated from production water after polymer flooding in an oil field. J. Hazard. Mater. 2010, 184, 105-110.

4. Shin, S.; Cho, Y.I. Temperature effect on the non-newtonian viscosity of an aqueous polyacrylamide solution. Int. Commun. Heat Mass 1993, 20, 831-844.

5. Henderson, J.M.; Wheatley, A.D. Factors effecting a loss of flocculation activity of polyacrylamide solutions: Shear degradation, cation complexation, and solution aging. J. Appl. Polym. Sci. 1987, 33, 669-684.

6. Gao, B.; Jiang, L.; Kong, D. Studies on rheological behaviour of hydrophobically associating polyacrylamide with strong positive salinity sensitivity. Colloid Polym. Sci. 2007, 285, 839-846.

7. Gu, J.D.; Roman, M.; Esselman, T.; Mitchell, R. The role of microbial biofilms in deterioration of space station candidate materials. Int. Biodeterior. Biodegrad. 1998, 41, $25-33$.

8. Matsuoka, H.; Ishimura, F.; Takeda, T.; Hikuma, M. Isolation of polyacrylamide-degrading microorganisms from soil. Biotechnol. Bioprocess Eng. 2002, 7, 327-330.

9. Busscher, W.J.; Novak, J.M.; Caesar-TonThat, T.; Sojka, R.E. Amendments to increase aggregation in United States Southeastern coastal plain soils. Soil Sci. 2007, 172, 651-658.

10. Hernandez, J.; Fayos, A.; Ferrus, M.A.; Owen, R.J. Random amplified polymorphic DNA fingerprinting of Campylobacter jejuni and C. coli isolated from human faeces, seawater and poultry products. Res. Microbiol. 1995, 146, 685-696.

11. Hahn, M.W. The microbial diversity of inland waters. Curr. Opin. Biotechnol. 2006, 17, $256-261$.

12. Silva, T.R.; Verde, L.C.L.; Santos Neto, E.V.; Oliveira, V.M. Diversity analyses of microbial communities in petroleum samples from Brazilian oil fields. Int. Biodeterior. Biodegrad. 2013, 81, $57-70$.

13. Silva, C.C.; Jesus, E.C.; Torres, A.; Sousa, M.P.; Santiago, V.; Oliveira, V.M. Investigation of bacterial diversity in membrane bioreactor and conventional activated sludge processes from petroleum refineries using phylogenetic and statistical approaches. J. Microbiol. Biotechnol. 2010, $20,447$.

14. Sette, L.; Simioni, K.M.; Vasconcellos, S.; Dussan, L.; Neto, E.S.; Oliveira, V. Analysis of the composition of bacterial communities in oil reservoirs from a southern offshore Brazilian basin. Antonie Leeuwenhoek 2007, 91, 253-266.

15. Li, H.; Yang, S.Z.; Mu, B.Z.; Rong, Z.F.; Zhang, J. Molecular phylogenetic diversity of the microbial community associated with a high-temperature petroleum reservoir at an offshore oilfield. FEMS Microbiol. Ecol. 2007, 60, 74-84.

16. Hollaway, S.L.; Faw, G.M.; Sizemore, R.K. The bacterial community composition of an active oil field in the northwestern gulf of mexico. Mar. Pollut. Bull. 1980, 11, 153-156. 
17. Grabowski, A.; Nercessian, O.; Fayolle, F.; Blanchet, D.; Jeanthon, C. Microbial diversity in production waters of a low-temperature biodegraded oil reservoir. FEMS Microbiol. Ecol. 2005, $54,427-443$.

18. Saitou, N.; Nei, M. The neighbor-joining method: A new method for reconstructing phylogenetic trees. Mol. Biol. Evol. 1987, 4, 406-425.

19. Wilkinson, L.; Friendly, M. The history of the cluster heat map. Am. Stat. 2009, 63, 179-184.

20. Nakamiya, K.; Kinoshita, S. Isolation of polyacrylamide-degrading bacteria. J. Ferment. Bioeng. 1995, 80, 418-420.

21. Chang, F.; Chen, L.; Chen, L.; Tian, Y.T.; Chen, W.L. Study on biodegradation of hydrolyzed polyacrylamide in polymer flooding produced wastewater. Chin. J. Environ. Eng. 2010, 11, 012.

22. Ma, F.; Wei, L.; Wang, L.; Chang, C.C. Isolation and identification of the sulphate-reducing bacteria strain $\mathrm{H} 1$ and its function for hydrolysed polyacrylamide degradation. Int. J. Biotechn. 2008, 10, $55-63$.

23. Huang, F.; Lu, X.Z. Study on biodegradation of partially hydrolyzed polyacrylamide used in oil-field. J. Wuhan Yejin Univ. Sci. Technol. 2001, 1, 012.

24. Kang, W.L.; Zhou, Y.; Wang, Z.W.; Meng, L.W.; Liu, S.R.; Bai, B.J. Mechanism of sulfide effect on viscosity of HPAM polymer solution. J. Cent. South Univ. Technol. 2008, 15, 115-117.

25. Wen, Q.X.; Chen, Z.; Zhao, Y.; Zhang, H.; Feng, Y. Biodegradation of polyacrylamide by bacteria isolated from activated sludge and oil-contaminated soil. J. Hazard. Mater. 2010, 175, 955-959.

26. Manz, W.; Amann, R.; Ludwig, W.; Vancanneyt, M.; Schleifer, K.H. Application of a suite of 16s rRNA-specific oligonucleotide probes designed to investigate bacteria of the phylum cytophaga-flavobacter-bacteroides in the natural environment. Microbiology 1996, 142, 1097-1106.

27. Liu, K.L.; Bu, D.P.; Wang, J.Q.; Yu, P.; Li, D.; Zhao, S.G.; He, Y.X.; Wei, H.Y.; Zhou, L.Y. Comparative analysis of rumen microbial communities in six species of cattle. J. China Agric. Univ. 2009, 14, 13-18.

28. Lei, P.; Nie, M.Q.; Wen, X.M.; Ge, B.Z.; Zhang, Z.J.; Zhao, W.M. Study to degradation characters of preponderant Flavobacterials strains in a mixture of anthracene, phenanthrene and pyrene. J. Xian Jiaotong Univ. 2004, 38, 657-660.

29. Woese, C.R.; Kandler, O.; Wheelis, M.L. Towards a natural system of organisms: Proposal for the domains archaea, bacteria, and eucarya. Proc. Natl. Acad. Sci. USA 1990, 87, 4576-4579.

30. Li, H.; Yang, S.Z.; Mu, B.Z.; Rong, Z.F.; Zhang, J. Molecular analysis of the bacterial community in a continental high-temperature and water-flooded petroleum reservoir. FEMS Microbiol. Lett. 2006, 257, 92-98.

31. Hallmann, C.; Schwark, L.; Grice, K. Community dynamics of anaerobic bacteria in deep petroleum reservoirs. Nat. Geosci. 2008, 1, 588-591.

32. Bursakov, S.; Liu, M.Y.; Payne, W.J.; LeGall, J.; Moura, I.; Moura, J.J.G. Isolation and preliminary characterization of a soluble nitrate reductase from the sulfate reducing organism Desulfovibrio desulfuricans ATCC 27774. Anaerobe 1995, 1, 55-60.

33. Mijaylova Nacheva, P.; Ramírez Camperos, E.; Sandoval Yoval, L. Treatment of petroleum production wastewater for reuse in secondary oil recovery. Water Sci. Technol. 2008, 57, 875-882.

34. Gao, C. Viscosity of partially hydrolyzed polyacrylamide under shearing and heat. J. Petrol. Explor Prod. Technol. 2013, 3, 203-206. 
35. Zhao, X.; Liu, L.; Wang, Y.; Dai, H.; Wang, D.; Cai, H. Influences of partially hydrolyzed polyacrylamide (HPAM) residue on the flocculation behavior of oily wastewater produced from polymer flooding. Sep. Purif. Technol. 2008, 62, 199-204.

36. MacDonald, J.; Belrose, J.; Xie, Y.F.; Jackson, M. Nonselective cation channels and links to hippocampal ischemia, aging, and dementia. Adv. Exp. Med. Biol. 2013, 961, 433-447.

37. Abdel-Halim, E.S.; Al-Deyab, S.S. Hydrogel from crosslinked polyacrylamide/guar gum graft copolymer for sorption of hexavalent chromium ion. Carbohydr. Polym. 2011, 86, 1306-1312.

38. Hatsis, P.; Lucy, C.A. Effect of temperature on retention and selectivity in ion chromatography of anions. J. Chromatogr. 2001, 920, 3-11.

39. Wang, Y.; Lin, S.; Zang, M.; Xing, Y.; He, X.; Lin, J.; Chen, T. Self-assembly and photo-responsive behavior of novel $\mathrm{ABC}_{2}$-type block copolymers containing azobenzene moieties. Soft. Matter. 2012, 8, 3131-3138.

40. Wang, L.Y.; Gao, C.X.; Mbadinga, S.M.; Zhou, L.; Liu, J.F.; Gu, J.D.; Mu, B.Z. Characterization of an alkane-degrading methanogenic enrichment culture from production water of an oil reservoir after 274 days of incubation. Int. Biodeterior. Biodegrad. 2011, 65, 444-450.

41. Guan, J.; Zhang, B.L.; Mbadinga, S.; Liu, J.F.; Gu, J.D.; Mu, B.Z. Functional genes (dsr) approach reveals similar sulphidogenic prokaryotes diversity but different structure in saline waters from corroding high temperature petroleum reservoirs. Appl. Microbiol. Biotechnol. 2014, 98, 1871-1882.

42. Guan, J.; Xia, L.P.; Wang, L.Y.; Liu, J.F.; Gu, J.D.; Mu, B.Z. Diversity and distribution of sulfate-reducing bacteria in four petroleum reservoirs detected by using $16 \mathrm{~s}$ rRNA and $d s r A B$ genes. Int. Biodeterior. Biodegrad. 2013, 76, 58-66.

43. Weisburg, W.G.; Barns, S.M.; Pelletier, D.A.; Lane, D.J. 16s ribosomal DNA amplification for phylogenetic study. J. Bacteriol. 1991, 173, 697-703.

44. Aranda Iv, R.; Dineen, S.M.; Craig, R.L.; Guerrieri, R.A.; Robertson, J.M. Comparison and evaluation of RNA quantification methods using viral, prokaryotic, and eukaryotic RNA over a 104 concentration range. Anal. Biochem. 2009, 387, 122-127.

45. Tamura, K.; Peterson, D.; Peterson, N.; Stecher, G.; Nei, M.; Kumar, S. MEGA5: Molecular evolutionary genetics analysis using maximum likelihood, evolutionary distance, and maximum parsimony methods. Mol. Biol. Evol. 2011, 28, 2731-2739.

46. Huber, T.; Faulkner, G.; Hugenholtz, P. Bellerophon: A program to detect chimeric sequences in multiple sequence alignments. Bioinformatics 2004, 20, 2317-2319.

47. Yu, Y.; Breitbart, M.; McNairnie, P.; Rohwer, F. FastGroupII: A web-based bioinformatics platform for analyses of large 16s rDNA libraries. BMC Bioinform. 2006, 7, 57.

48. Altschul, S.F.; Madden, T.L.; Schäffer, A.A.; Zhang, J.; Zhang, Z.; Miller, W.; Lipman, D.J. Gapped BLAST and PSI-BLAST: A new generation of protein database search programs. Nucleic Acids Res. 1997, 25, 3389-3402.

(C) 2015 by the authors; licensee MDPI, Basel, Switzerland. This article is an open access article distributed under the terms and conditions of the Creative Commons Attribution license (http://creativecommons.org/licenses/by/4.0/). 